\title{
The geography of thinking
}

John Mole

\begin{abstract}
People in different cultures are taught to think differently. How we gather information, process, rationalise, justify and communicate our ideas is culturally determined. Europe is divided between the pragmatic, inductive thinking of North Sea cultures and the rationalist thinking of the rest of the continent. Westerners and Asians have different mental skills and capacities deriving from the nature of written and spoken language, the relative importance of learning by rote or investigation and the social environment. Western children are expected to ask questions and test ideas for themselves, while in Asia it is unacceptable to question anyone senior in age or authority, including teachers. Westerners base thinking on reason; Asians base thinking on harmony. Whenever people of different cultures work together, different ways of thinking create barriers to understanding and communication. This applies to many spheres of work, including the medical profession.
\end{abstract}

KEY WORDS: communication, cross-cultural, culture, language, problem-solving, reasoning, thinking

How do you teach children arithmetic? By counting beads and playing with rods or by teaching them multiplication tables? People in different cultures are taught to think differently. At the beginning of the seventeenth century, the English philosopher Francis Bacon formulated the 'scientific method'. The essence is that one gathers observable facts from which a general conclusion or hypothesis can be drawn. This is known as induction, the inferring of a general law from particular instances. A few years later, the French philosopher René Descartes formulated a theory of knowledge derived from the single indisputable premise that he was thinking, therefore he existed, Cogito ergo sum. This is known as deduction, the inferring of particular instances from a general law.

Since the Renaissance, Europe has been divided between the pragmatic, empirical, inductive thinking of Anglo-Saxon and North Sea cultures and the rationalist, deductive thinking of the rest of the continent. Anglo-Saxons are uncomfortable with theories and generalisations and concepts. They prefer to deal with data. Other Europeans are uncomfortable with dealing with data unless it is in the context of an idea or a system. The difference is reflected in the history of European philosophy and in the way our children are taught in schools, in the way football teams are managed and how we structure memos, reports and presentations. In Britain, public debates about the European Union, the Euro, transport policy and public services are notable for their lack of theoretical content, while in France they are driven by concept more than pragmatism.

What they have in common is that they are linear modes of thinking. They are based on logical reasoning, categorisation and a belief in cause and effect. Other ways of thinking - intuition, emotional intelligence, lateral thinking, free association and flashes of insight from nowhere - are mistrusted unless they can be logically substantiated.

Western intellectual tradition is based on the exercise of reason based on provable links of cause and effect. Confronted with a number of facts or premises, we are taught to sort them into categories and eliminate those that have no causal connection. We analyse complexity into simple constituents and arrange them in simple lines of argument with a beginning, middle and end. This is how we structure the history of the universe from Big Bang to Black Hole and how we structure a report from Introduction through Results, Discussion and Conclusions.

The emphasis on reason and linear thinking is most pronounced in those western European and American cultures that experienced the intellectual revolution of the eighteenth century known as the Enlightenment. At the heart of the Enlightenment was the belief that the exercise of reason is the only basis of spiritual truth, scientific knowledge and social progress. Other cultures did not experience the Enlightenment or did so at second hand as they Europeanised their cultures. They may have conventions of thinking that admit such processes as associative and lateral thinking and allow themselves to be influenced by non-rational influences such as precedent or divine revelation.

Within these broad categories of thinking, different cultures may use different intellectual tools to arrive at a conclusion. They can be misunderstood or misinterpreted as socially inappropriate. The Socratic irony often encountered in Hispanic culture,
John Mole

Author and Consultant in Comparative Culture 
in which humility or pretended ignorance is a device for questioning, can seem like stupidity to others. Germanic scepticism, in which arguments are habitually doubted, can seem aggressive and rude to those who associate ideas with the people who voice them. Dialectic taught to French people from an early age, in which a thesis is instinctively countered by antithesis to arrive eventually at a synthesis, can seem like deliberate obstructiveness. Middle Eastern discursiveness that explores every aspect of a proposition from all possible angles can seem like obfuscation. And so on.

In reality, we use all these ways of thinking. Pragmatists need some kind of hypothesis or intuition in order to select data to work on. Rationalists need some data to germinate ideas. Even Descartes needed an observable premise, that he was thinking. But different cultures give different emphasis to different modes or do not admit them at all.

The most striking difference is between Asian and western ways of thinking. The Chinese language does not have tenses. Exactly the same word describes what someone did, does or will do. Nor does it have inflections - alterations of words to communicate cases and conjugations like singular or plural, subject or object. What gives words their sense is not how they are formally linked by grammar but the word order, where they stand in relation to each other. In the western languages, words are connected by strict rules of form and grammar so word order is less important than the intrinsic connections between words. So even before they go to school Chinese and western children learn different ways of making connections between ideas.

At school Westerners and Asians are trained in different mental skills and capacities. In Japan you need to learn about 2,000 characters for basic literacy. In China you need to know a minimum of 1,500 characters for very basic literacy and 3,000 characters to read a newspaper. College graduates know about 7,000 . Most of the characters represent single words and some can be combined to make compounds. The same Chinese character can correspond to many different meanings when it is used in conjunction with different characters or in different context. Sometimes it can have more than one pronunciation, each of which corresponds to a different meaning. While it is possible to deduce the meaning of some characters from others, for the most part they have to be learned off by heart. In the western phonetic system we learn between 25 and 50 characters, depending on the language, and a number of letter combinations that are not phonetic. We then learn an extensive set of spelling and grammar rules for combining them.

So while a western and an Asian child at the end of primary school have about the same level of literacy, the mental processes that they developed to become so are different. Asian memories are further developed by a predominantly didactic teaching system with learning by rote and fact based testing. In most western countries there is a greater emphasis on empirical learning.

While western thinking strives for order, Asian thinking aspires to harmony. Rather than look for ways of reducing facts or premises into categories, eliminating what does not logically fit, it looks for ways of associating them into meaningful patterns which accommodate rather than resolve conflicting premises or facts. Associative thinking is a syncretic, holistic process that looks for relationships even though no causal link is apparent. Associative thinking makes connections rather than choices and has a greater tolerance of ambiguity and contradiction than Westerners are used to. A good example is the difference between Chinese medicine - holistic and symptom based, and western medicine - reductionist and analytic.

Social values influence how we think. In most western countries, a stated goal of education policy is to foster a spirit of inquiry. Children are taught and encouraged to ask questions, to test facts and ideas for themselves, to develop a healthy scepticism as a basis for the development of their own ideas. Many western teachers base their teaching style on dialogue and inquiry. In traditional Asian culture based on Confucianism it is not acceptable to ask questions of anyone senior in age or authority, including teachers. Discussion and debate is acceptable only among peers. It is disquieting for a western lecturer in a classroom of Asian students to have no interactivity or feedback. The compensation is that they have better listening skills and a longer attention span than their western equivalents. And they do just as well, if not better, in examinations.

In cross-cultural encounters with Asians, Westerners should not expect the cut and thrust of argument, the search for simple solutions to problems and resolutions of conflict. Direct questions may be out of place and the eliciting of alternatives or preferences may meet with diffidence. Equally, Asians should not expect from Westerners intellectual subtlety, an ability to deal with complexity, or understanding of a wider picture.

Different ways of thinking are not mutually exclusive but are given different emphasis in different cultures. If Westerners were purely analytical they would have no poetry or religion. If Asians were purely associative they would not be able to build cars and computers. Nor are they static. For example, in the UK the evolving curriculum in university medical schools and the introduction of evidence-based medicine indicate changes in an underlying intellectual framework.

\section{What has this got to do with me?}

Whenever people of different cultures work together there is a possibility that different ways of thinking create barriers to understanding and communication. For example, within the European Union the mutual recognition of medical qualifications or the harmonising of curricula demand an understanding of intellectual constructs as much as content. On a more practical level, practitioners from different cultures in the same workplace may have very different approaches to diagnosis and other forms of problem solving. Research teams from different countries involved in the same project may have different approaches, methods, and ways of presenting their results. Examination candidates from overseas, especially in vivas, may not understand the meaning or point of a question because its intellectual frame of reference is alien to them. And so on.

A European child brought up by Asians will think like an 
Asian; an Asian child brought up by Europeans will think like a European. On a psychological or cerebral level it seems that we all think in the same way, although scientists are uncertain how. In fact, the issue is not about how we think but how we think about thinking. What is culturally determined is how we are trained to process, rationalise, justify and communicate our ideas.

\section{Acknowledgments}

I am grateful to Ephraem Tsui, MSc Clin Psy (London), and Damian J. Mole, MRCS, for their help with this article. 